\title{
Temperature Dependent Luminescence Spectra of Synthetic and Natural Alexandrite $\left(\mathrm{BeAl}_{2} \mathrm{O}_{4}: \mathrm{Cr}^{3+}\right)$
}

\author{
${ }^{1}$ Neilo Marcos Trindade, ${ }^{2}$ Américo Tabata, ${ }^{2}$ Rosa Maria Fernandes Scalvi, \\ ${ }^{2}$ Luis Vicente de Andrade Scalvi* \\ ${ }^{1}$ Anhanguera Educacional, Sorocaba, Brazil \\ ${ }^{2}$ UNESP- State University of São Paulo (Dept. Physics - FC), Bauru, Brazil \\ E-mail: scalvi@fc.unesp.br
}

Receives July $16^{\text {th }}, 2010$; revised October $11^{\text {th }}, 2010$; accepted March $15^{\text {th }}, 2011$.

\begin{abstract}
Results of photoluminescence measurements for natural and synthetic alexandrite $\left(\mathrm{BeAl}_{2} \mathrm{O}_{4}: \mathrm{Cr}^{3+}\right)$ are presented, where the samples are excited by the $488 \mathrm{~nm}$ line of an $\mathrm{Ar}^{+}$laser, at different temperatures. The main issue is the analysis of the $\mathrm{Cr}^{3+}$ transition in the chrysoberyl matrix $\left(\mathrm{BeAl}_{2} \mathrm{O}_{4}\right)$, with major technological application as active media for laser action. Results indicate anomalous behavior of $\mathrm{Cr}^{3+}$ transition depending on the measurement temperature. A simple model to explain the phenomena is suggested.
\end{abstract}

Keywords: Alexandrite, Luminescence, $\mathrm{Cr}^{3+}$ Transitions, Optical Absorption

\section{Introduction}

The use of alexandrite as an active media for laser action, with emission in the range $700-800 \mathrm{~nm}$ [1], has appeared for the first time in 1978 [2]. Since then, this material became technologically important. Recently, many reports show wide application of the alexandrite laser, in medicine as well as for atmospheric studies [3,4].

Alexandrite structure may be visualized as approximately hexagonal close packed (hcp), with unit cell of four molecules, with eight $\mathrm{Al}^{3+}$ ions, occupying distorted octahedral sites and four $\mathrm{Be}^{2+}$ ions, occupying distorted tetrahedral sites, formed by oxygen located at plans perpendicular to c axis. The distortion from a perfect hcp structure of oxygen ions give birth to the appearing of two sites of distinct symmetries: $\mathrm{Al}_{1}$, located at inversion sites and $\mathrm{Al}_{2}$, located at mirror sites [5,6]. $\mathrm{Cr}^{3+}$ ions are incorporated in the octahedral of reflection and inversion symmetries and may be denoted by $\mathrm{Cr}_{s}^{3+}$ and $\mathrm{Cr}_{i}^{3+}$, respectively.

The octahedrally coordinated $\mathrm{Al}_{2}$ site is supposed to be larger when compared to $\mathrm{Al}_{1}$, which can be explained by the length of the bond Al-O (1.938 $\AA$ ), which is longer than for $\mathrm{Al}_{1}(1.890 \AA)$, resulting on a larger polyhedral volume [7]. The $\mathrm{Al}_{2}$ site, due to its lager size, is preferentially occupied by $\mathrm{Cr}^{3+}$ ions, and then it is responsible for the optical properties of alexandrite [8]. Then, $\mathrm{Cr}_{\mathrm{s}}^{3+}$ ions are characterized by a high probability of electric dipole transition. The magnetic dipole transitions of the $\mathrm{Cr}_{i}^{3+}$ do not contribute significantly to the optical absorption and emission of this material. Besides, they are excluded from the laser process, equilibrating or reducing the excitation energy of $\mathrm{Cr}_{s}^{3+}$ ions [5]. Then, the ratio of $\mathrm{Cr}_{\mathrm{s}}^{3+}$ and $\mathrm{Cr}_{i}^{3+}$ concentrations become a determinant parameter for the alexandrite optical efficiency. EPR measurements indicate that, in general, the $\mathrm{Cr}^{3+}$ ion enters in the $\mathrm{BeAl}_{2} \mathrm{O}_{4}$ lattice in a ratio of about $75 \%$ of $\mathrm{Al}_{2}$ and $25 \%$ of $\mathrm{Al}_{1}$, for the natural sample as well as for synthetic material, showing variations depending on the relative quantity of $\mathrm{Cr}_{2} \mathrm{O}_{3}$ in the sample [9].

In the luminescence spectra, the $\mathrm{Cr}_{s}^{3+}$ lines are called $R_{1}$ and $R_{2}$, and the lines of $\mathrm{Cr}_{\mathrm{i}}^{3+}$ are called $\mathrm{S}_{1}$ and $\mathrm{S}_{2}$. As experimentally observed [6], the $\mathrm{R}$ lines show up precisely in the same wavelength, 680.4 and $678.5 \mathrm{~nm}$, respectively, at room temperature, in both spectra: optical absorption and emission. In the emission spectra, the lines $S_{1}$ and $S_{2}$ show up around 695.8 and $689.9 \mathrm{~nm}$ and in the absorption spectra they are seen as narrow lines at 655.7, 649.3 and $645.2 \mathrm{~nm}[10,11]$.

\section{Experimental}

Alexandrite stones come from Minas Gerais state in Brazil, and show a dark green color, due to the presence of clusters. Samples have been cut such that parallel plans between the faces were provided, leading to an average 
thickness of $1.5 \mathrm{~mm}$. The synthetic sample has been grown by H. P. Jenssen and R. Morris (from Allied Signal Inc, U.S.A.), by the Czochralsky method as mentioned elsewhere [6]. The thickness is $2.3 \mathrm{~mm}$ and show perfectly parallel faces.

For luminescence excitation it is used an $\mathrm{Ar}^{+}$laser tuned at $h v=2.51 \mathrm{eV}$. In the excitation system, the laser beam is irradiated through a chopper, being redirected to the sample, which is placed inside a closed cycle He cryostat. The emitted light from the sample (photoluminescence) is sent to a spectrophotometer coupled to a germanium detector, where the electrical signal is amplified by a lock-in amplifier, linked to a computer which controls the spectrophotometer and collects the obtained data.

\section{Results and Discussion}

Figure 1 shows the Luminescence spectra for the synthetic alexandrite sample measured at several temperatures. Figure 1(a) evidences the lines R, and Figure 1(b), lines S. Below room temperature, the luminescence spectra is dominated by the $\mathrm{R}$ lines of individual $\mathrm{Cr}$ ions and the $\mathrm{S}$ lines, originated from exchange-coupled pairs of chromium ions [11].

The luminescence of $\mathrm{R}$ and $\mathrm{S}$ lines points towards a dependency with the measurement temperature, as can be observed in Figures 1(a) and 1(b), for the synthetic sample.

In Figure 1(a), the relative intensity of $\mathrm{Cr}_{\mathrm{s}}^{3+}$ lines, $\mathrm{R}_{1}$ and $R_{2}$, present always the same behavior, with the intensity of line $R_{1}$ being higher than for line $R_{2}$, and the difference between them decreases with temperature. As the temperature is raised, the line $\mathrm{R}_{1}$ has an intensity decrease, whereas the line $R_{2}$ show intensity increase until $135 \mathrm{~K}$. Above this temperature, this line also shows a gradual intensity decrease. For the $\mathrm{Cr}_{\mathrm{i}}^{3+}$ lines, $\mathrm{S}_{1}$ and $\mathrm{S}_{2}$, shown in Figure 1(b), the line $S_{1}$ is more intense than line $S_{2}$. The variation in the intensities of these lines is explained as an indicative that more then one type of carrier relaxation mechanism is present [12]. Figure 1(b) shows that line $S_{1}$ decreases, whereas line $S_{2}$ has a slight intensity increase until about $135 \mathrm{~K}$, and above that a regular intensity decrease.

The variation in intensities of $\mathrm{R}$ lines as well as $\mathrm{S}$ lines for natural alexandrite is shown in Figure 2. The variation of both lines occurs in a similar way for this sample, as shown in the photoluminescence spectra of Figures 2(a) and 2(b). In the spectra, it is also possible to observe that the lines $\mathrm{R}$ and $\mathrm{S}$ change position, starting from 135 $\mathrm{K}$, shifting to higher wavelengths (lower energy), followed by a wavelength broadening of these lines. Moreover, in a comparison of synthetic and natural samples, it can be noticed that the lines position is practically in the

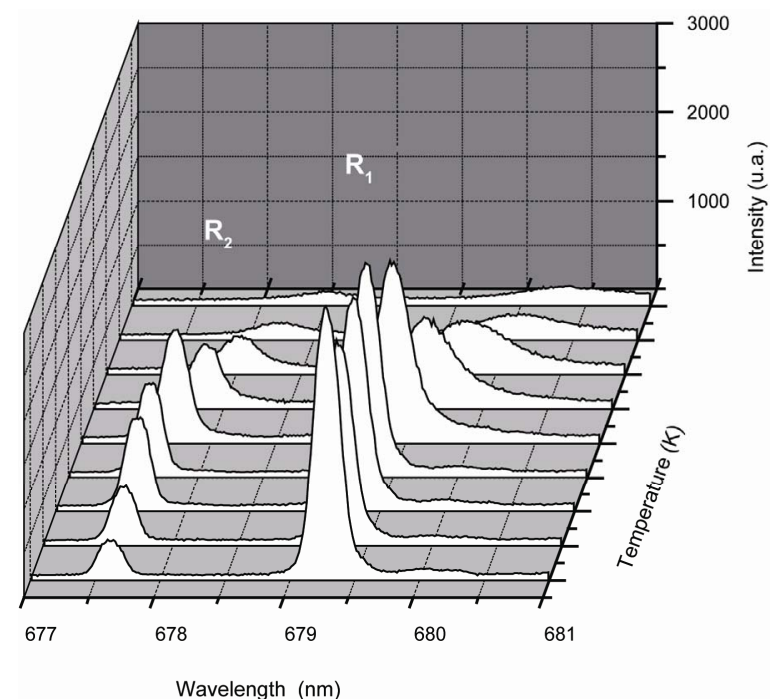

(a)

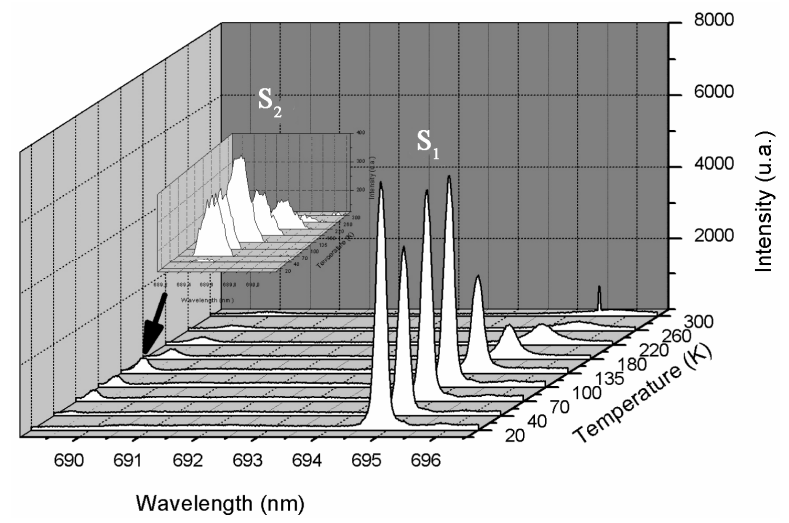

(b)

Figure 1. Luminescence spectra for the synthetic alexandrite sample as function of temperature. (a) Lines $R$, (b) Lines S.

same wavelength.

Considering that either the natural as the synthetic sample shows the same effect in the intensity of emission lines measured at different temperatures, the explanation concerning the behavior of lines $\mathrm{R}$ and $\mathrm{S}$, can be done by analogy. A simple model is proposed and is shown in Figure 3, where the electron and hole ground states are represented. Vertical lines stand for radiative transition and oblique lines represent the electron transfer from an electronic level to another. $t$ represents the lifetime of the carrier in the level and is associated with the transition probability between two levels.

In this model, it is supposed that initially there is no interaction between electronic levels $\mathrm{R}$ and S. Free carriers of a site probably do not interact with the carriers from another level, and with the associated levels of $\mathrm{Cr}^{3+}$ clusters. Then, the probability that carriers from level $\mathrm{R}$ 


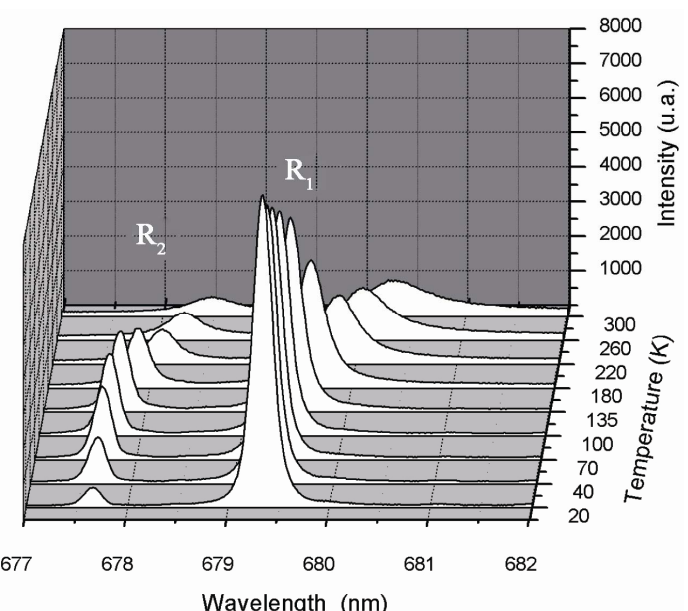

(a)

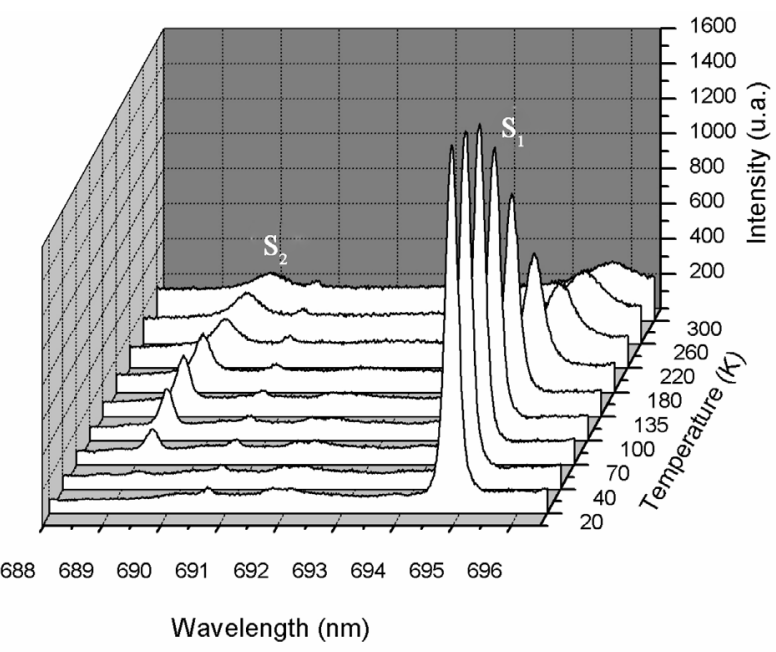

(b)

Figure 2. Luminescence spectra for natural sample as function of temperature (a) Lines $R$ and (b) Lines S.

are transferred to level S and vice-versa is very low, as well as from levels $\mathrm{R}$ or $\mathrm{S}$ to the levels associated with $\mathrm{Cr}^{3+}$ clusters.

Then, at low temperature, electrons excited by optical pumping lose energy by phonon emission (lattice vibration) and are trapped by levels $\mathrm{R}$ and $\mathrm{S}$. Then, they recombine with holes from the ground state, generating the lines $R_{1}, R_{2}, S_{1}$ and $S_{2}$. With the temperature increase, as the intensity of lines $R_{1}$ and $S_{1}$ decrease due to interaction between electrons and phonons, the emission associated to lines $R_{2}$ and $S_{2}$ show inverse behavior, and present intensity increase. This behavior is observed until $135 \mathrm{~K}$. Above that temperature, the intensities decrease due to the electron-phonon coupling. This behavior is explained as follows: as the temperature is increased, some $\mathrm{R}_{1}$ carriers are excited back to $\mathrm{R}_{2}$. This is possible if the lifetime $t_{21}$ is long enough for the excitation or at

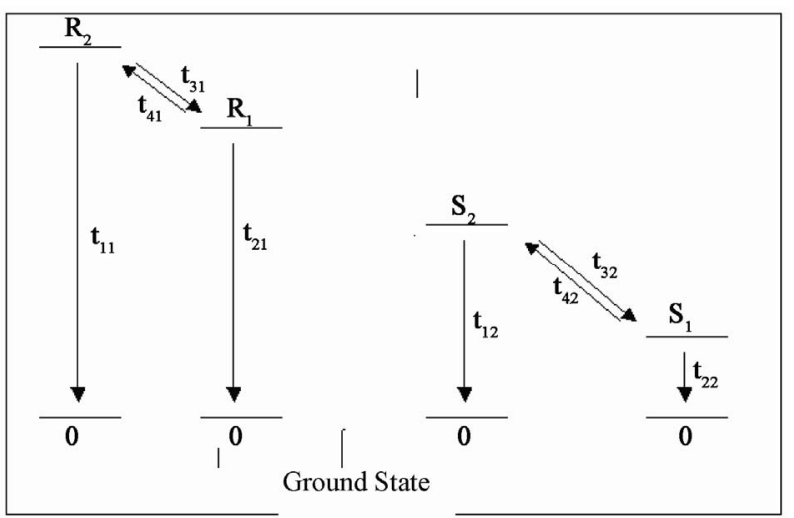

Figure 3. Diagram representing the transfer ratio between emission levels and lifetime $(t)$.

least of the same order of magnitude of $t_{41}$, the lifetime for excitation back of carriers from $R_{1}$ to $R_{2}$. On the other hand, if the lifetime $t_{31}$ is longer than $t_{11}$, the carriers in $\mathrm{R}_{2}$ tend to recombine radiatively with holes in the ground state instead of finishing in the $\mathrm{R}_{1}$ level, making the emission intensity associated with $\mathrm{R}_{2}$ to increase. With higher temperature increase, more carriers in $\mathrm{R}_{1}$ will gain energy to populate $R_{2}$, and then, the intensity grows with the temperature increase. However, above $135 \mathrm{~K}$, the electron-phonon coupling becomes very strong and the relaxation via phonons (non-radiative) becomes dominant. In this case, the intensity of lines $\mathrm{R}_{1}$ in the photoluminescence spectra decreases. The same process may be applied to the transition involving $\mathrm{S}$ levels.

We have observed that it leads to some interesting variation in the luminescence dependency with temperature. Lines $\mathrm{R}$ and $\mathrm{S}$ remains fixed at their wavelengths until about $135 \mathrm{~K}$, where a peak shift takes place to higher wavelengths (lower energy), followed by a wavelength broadening of theses lines, shown in the emission spectra. This peak shift is associated with the increase of the alexandrite unit cell with temperature.

The luminescence spectra also allow analyzing the difference between wavelengths of emission lines in these samples, as can be seen in Table 1.

It can be verified in Table $\mathbf{1}$ that the wavelength separation between $\mathrm{S}$ lines is about three times larger than the

Table 1. $\mathbf{R}_{1}, \mathbf{R}_{2}, S_{1}$ and $S_{2}$ lines position and separation ( $\left.\Delta \lambda\right)$ between these lines at room temperature, for synthetic and natural alexandrite samples.

\begin{tabular}{ccccc}
\hline Sample & $\mathrm{R}_{2}(\mathrm{~nm})$ & $\mathrm{R}_{1}(\mathrm{~nm})$ & $\mathrm{S}_{2}(\mathrm{~nm})$ & $\mathrm{S}_{1}(\mathrm{~nm})$ \\
\hline Synthetic & 678.5 & 680.3 & 689.9 & 695.7 \\
& \multicolumn{2}{c}{$\Delta \lambda=1.8$} & \multicolumn{2}{c}{$\Delta \lambda=5.8$} \\
Natural & 678.5 & 680.3 & 689.9 & 695.8 \\
& \multicolumn{2}{c}{$\Delta \lambda=1.8$} & $\Delta \lambda=5.9$ \\
\hline
\end{tabular}


separation between $\mathrm{R}$ lines. This behavior indicates a stronger low symmetry component of the crystalline field for ions located in a inversion center [13].

\section{Conclusions}

Photoluminescence measurements carried out at several temperatures for alexandrite samples have shown up as very relevant to the analysis of $\mathrm{Cr}^{3+}$ transition in this material, because it is related to its potentiality to laser activity. The temperature dependency of the emission spectra exhibits an anomalous behavior for natural samples as well as for the synthetic one, compared to most materials, for instance, semiconductors. Then, a simple model is proposed, based on electronic transitions of levels $\mathrm{R}$ and $\mathrm{S}$, characteristic of $\mathrm{Cr}^{3+}$ transitions.

\section{Acknowledgements}

This work was supported by CAPES, CNPq, FAPESP and FUNDUNESP. The authors are grateful to Prof. Tomaz Catunda for the synthetic sample.

\section{REFERENCES}

[1] P. Fabeni, G. P. Pazzi and L. Salvini, "Impurity Centers for Tunable Lasers in the Ultraviolet and Visible Regions," Journal of Physics and Chemistry of Solids, Vol. 52, No. 1, 1991, pp. 299-317. doi:10.1016/0022-3697(91)90069-C

[2] G. V. Bukin, V. N. Matrosov, V. P. Orekhova, Yu. L. Remigailo, B. K. Sevastyanov, E. G. Syomin, V. P. Solntsev and E. G. Tsvetkov, "Growth of Alexandrite Crystals and Investigation of Their Properties," Journal of Crystal Growth, Vol. 52, No. 2, April 1981, pp. 537-541. doi:10.1016/0022-0248(81)90335-3

[3] L. Li, T. Kono, W. F. Groff, H. H. Chan, Y. Kitazawa and M. Nozaki, "Comparison Study of a Long-Pulse Pulsed Dye Laser and a Long-Pulse Pulsed Alexandrite Laser in the Treatment of Port Wine Stains," Journal of Cosmetic and Laser Therapy, Vol. 10, No. 1, March 2008, pp. 12-15. doi:10.1080/14764170701817023

[4] S. C. Collins, T. D. Wilkerson, V. B. Wickwar, D. Rees, J. C. Walling and D. F. Heller, "The Alexandrite Ring Laser: A Spectrally Narrow Lidar Light Source for Atmospheric Fluorescence and Absorption Observations,” In: A. Ans- mann, R. Neuber, P. Rairoux and U. Wandinger, Eds., Advances in Atmospheric Remote Sensing with Lidar, Springer Verlag, Berlin, 1997, pp. 577-580.

[5] B. K. Sevast'yanov, "Excited-State Absorption Spectroscopy of Crystal Doped with $\mathrm{Cr}^{3+}, \mathrm{Ti}^{3+}$, and $\mathrm{Nd}^{3+}$ Ions, Review," Crystallography Reports, Vol. 48, No. 6, 2003, pp. 989-1011.

[6] R. M. F. Scalvi, M. S. Li and L. V. A. Scalvi, "Annealing Effects on Optical Properties of Natural Alexandrite," Journal of Physics Condensed Matter, Vol. 15, No. 43, November 2003, pp. 7437-7443. doi:10.1088/0953-8984/15/43/025

[7] S. U. Weber, M. Grodzicki, W. Lottermoser, G. J. Redhammer, G. Tippelt, J. Ponahlo and G Amthauer, “57Fe Mossbauer Spectroscopy, X-Ray Single-Crystal Diffractometry, and Electronic Structure Calculations on Natural Alexandrite," Physics and Chemistry of Minerals, Vol. 34, No. 7, 2007, pp. 507-515. doi:10.1007/s00269-007-0166-6

[8] G. V. Bukin, A. V. Eliseev, V. N. Matrosov, V. P. Solntsev, E. I. Kharchenko and E. G. Tsvetjov, "The Growth and Examination of Optical Properties of Gem Alexandrite," Proceedings of the XI General Meeting of IMA, Novosibirsk, 1980, pp. 317-328.

[9] H. Rager, A. Bahshandh-Khiri and K. N. Schmetzer, "Investigation of the Intracrystalline $\mathrm{Cr}^{3+}$ Distribution in Natural and Synthetic Alexandrites,” Neues Jahrbuch für Mineralogie Monatshefte, Vol. 12, 1998, pp. 545-557.

[10] R. C. Powell, L. Xi, X. Gang and G. J. Quarles, "Spectroscopic Properties of Alexandrite Crystals,” Physical Review B, Vol. 32, No. 5, September 1985, pp. 27882797. doi:10.1103/PhysRevB.32.2788

[11] S. P. Jamilson and G. F. Imbusch, “Temperature Dependence of the Luminescence from Heavily Doped ruby,” Journal of Luminescence, Vol. 75, No. 2, September 1997, pp. 143-147.

[12] K. L. Schepler, "Fluorescence of Inversion Site $\mathrm{Cr}^{3+}$ Ions in Alexandrite," Journal of Applied Physics, Vol. 56, No. 5, September 1984, pp. 1314-1318. doi:10.1063/1.334119

[13] B. Suchocki , G. D. Gilliland, R. C. Powell and J. M. Bowen, "Spectroscopic Properties of Alexandrite Crystals II.,” Journal of Luminescenc, Vol. 37, No. 1, April 1987, pp. 29-37. doi:10.1016/0022-2313(87)90179-7 